\title{
Impact of Intraoperative Blood Loss on the Survival of Patients With Stage II/III Colorectal Cancer: A Multicenter Retrospective Study
}

\author{
HIROSHI TAMAGAWA ${ }^{1}$, MASAKATSU NUMATA ${ }^{1}$, TORU AOYAMA ${ }^{1}$, KEISUKE KAZAMA $^{1}$, \\ YOSUKE ATSUMI ${ }^{1}$, KENTA IGUCHI ${ }^{1}$, SHO SAWAZAKI ${ }^{2}$, SUMITO SATO ${ }^{1}$, KAZUKI KANO ${ }^{3}$, \\ TAKASHI OHSHIMA ${ }^{3}$, TAKANOBU YAMADA ${ }^{3}$, TENI GODAI ${ }^{4}$, AKIO HIGUCHI $^{2}$, \\ HIROYUKI SAEKI $^{2}$, NORIO YUKAWA ${ }^{1}$ and YASUSHI RINO ${ }^{1}$ \\ ${ }^{1}$ Department of Surgery, Yokohama City University, Yokohama, Japan; \\ ${ }^{2}$ Department of Surgery, Yokohama Minami Kyosai Hospital, Yokohama, Japan; \\ ${ }^{3}$ Department of Gastroenterological Surgery, Kanagawa Cancer Hospital, Yokohama, Japan; \\ ${ }^{4}$ Department of Surgery, Fujisawa Shonandai Hospital, Fujisawa, Japan
}

\begin{abstract}
Background: Resection of the primary lesion with radical lymph node dissection is the most promising treatment avenue for patients with cancer. On the other hand, these procedures often induce excessive intraoperative blood loss (IBL) and require perioperative blood transfusion. The influence of IBL on the long-term postoperative outcomes of patients with digestive cancer is controversial. We investigated the impact of IBL on survival and recurrence after curative surgery in patients with colorectal cancer (CRC) in a single study group. Patients and Methods: In total, 1,597 patients who underwent radical resection for CRC at three group hospitals between 2000 and 2019 were reviewed. Patients were classified into a group with high IBL $(\geq 200 \mathrm{ml})$ or low IBL $(<200 \mathrm{ml})$. The risk factors for disease-free (DFS) and overall (OS) survival were analyzed. Results: A total of 489 and 1,108 patients were classified into the high and low IBL groups, respectively. The OS and DFS rates at 5 years after surgery were $89.3 \%$ and $63.4 \%$, respectively, for the high IBL group and $96.9 \%$ and $77.8 \%$
\end{abstract}

This article is freely accessible online.

Correspondence to: Hiroshi Tamagawa, MD, Ph.D., Department of Surgery, Yokohama City University, 3-9 Fukuura, Kanazawa-ku, Yokohama, Kanagawa 236-0004, Japan. Tel: +81 457872800, Fax: +81 457860226, e-mail: rinta77-nosuke@ amber.plala.or.jp and Toru Aoyama, MD, PhD, Department of Surgery, Yokohama City University, 3-9 Fukuura, Kanazawa-ku, Yokohama, Kanagawa 2360004, Japan. Tel: +81 457872800, Fax: +81 457860226, e-mail: taoyama@lilac.plala.or.jp

Key Words: Colorectal cancer, intraoperative blood loss, survival, recurrence. for the low IBL group; these differences were statistically significantly $(p<0.001)$. The multivariate analysis demonstrated that IBL was a significant independent risk factor for OS and DFS. Conclusion: The amount of IBL was associated with significant differences in the OS and DFS of patients with stage II/III CRC who received curative resection. The surgical procedure, surgical strategy, and perioperative care should be carefully planned to avoid causing IBL.

Colorectal cancer (CRC) remains the fourth cancer-specific cause of death worldwide and the second and third leading cause in males and females, with an estimated 1.09 million new cases and 551,200 deaths occurring in 2018 (1). Complete resection is essential to obtain a cure in cases of CRC. 5-Year relative survival of patients diagnosed with CRC was $90.1 \%$ for patients with localized stage, $69.2 \%$ for patients with regional spread, and $11.7 \%$ for patients with distant tumor spread. In particular, patients with stage II/III CRC often develop recurrence, even after complete curative resection. It is reported that approximately $21-42 \%$ of patients with stage II/III CRC develop recurrent disease, such as local recurrence or distant metastasis (2). Recently, adjuvant treatment was introduced for stage II/III CRC and has improved patient survival $(3,4)$. Consequently, it is important to determine prognostic factors for stage II/III $\mathrm{CRC}$, as it would facilitate the selection of patients who can benefit from more aggressive treatment. In patients with CRC, Burrow and Tartter (5) were the first to report the risk associated with perioperative blood transfusion in 1982 . Since then, some reports have documented the relationship between intraoperative blood loss (IBL) and a poor prognosis of patients with some types of cancer (6-11). However, 
research on the association between IBL and the long-term outcomes of patients with CRC remains limited.

The purpose of this multicenter retrospective study was to determine whether overall (OS) and disease-free (DFS) survival were affected by the degree of intraoperative blood loss in patients who underwent curative resection of stage II/III CRC.

\section{Patients and Methods}

Study design. The database of Yokohama City University (Department of Surgery) and three group facilities, which included data obtained between January 2000 and December 2019, was retrospectively reviewed. According to these records, a total of 2,205 patients with CRC underwent radical resection of primary lesions. Of these, we excluded cases with pathological stage I or IV, synchronous or multiple cancer, simultaneous operation of other organs, and non-curative resection. Finally, 1,597 patients who were diagnosed with pathological stage 11/111, and who underwent curative resection were enrolled in this study.

All procedures performed in the study were in accordance with the ethical standards of the institutional research committee (Yokohama City University Institutional Review Board; approval no. 170700003) and with the 1964 Helsinki declaration and its later amendments or comparable ethical standards.

Outcomes of interest. The primary outcome of this cohort study was 5 -year disease-free survival (DFS). The secondary outcomes were 5-year OS and short-term outcomes, such as operative time and the incidence of postoperative complications. OS was defined as the period from the first resection of the primary lesion until death. DFS was defined as the period from the first resection of the primary lesion until recurrence or death. Operative time was defined as the time from skin incision for the first port to the completion of all surgical incisions. Postoperative complications were assessed by the Clavien-Dindo classification system (12). This study recorded grade 3-5 postoperative complications that occurred during hospitalization and those that occurred within 30 days after surgery.

Evaluations and statistical analyses. The optimal cut-off value of IBL was investigated by a receiver operating characteristic (ROC) curve analysis. The significance of the correlation between the IBL and clinicopathological parameters was determined using Fisher's test or the chi-squared test. OS and DFS curves were determined using the Kaplan-Meier method and were compared by a log-rank test. OS and DFS were evaluated by univariate and multivariate analyses using a Cox proportional hazards model. $p$-Values of less than 0.05 were considered to indicate statistical significance. The survival data were derived from hospital records or from the city registry system. The SPSS software program (v26. J Win; SPSS, Chicago, IL, USA) was used for all statistical analyses.

\section{Results}

Patient characteristics and short-term outcomes. IBL of 200 $\mathrm{ml}$ exhibited the maximum sensitivity and specificity on the ROC plot and was set as the optimum cut-off value for classification $(95 \%$ confidence interval $=0.573-0.694$; area

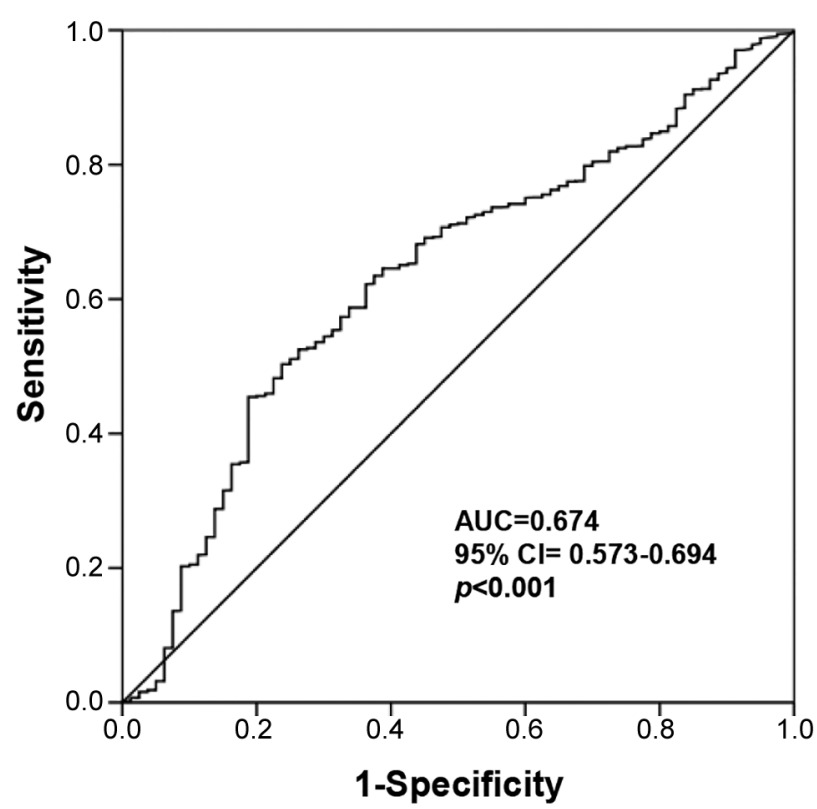

Figure 1. A: Receiver operating characteristic curve analysis to determine the optimal cut-off value of intraoperative blood loss (IBL) in patients who underwent potentially curative surgery for stage II pancreatic cancer. AUC: Area under the curve; CI: confidence interval.

under the curve $=0.674 ; p<0.001$, Figure 1). Patients were divided into groups with high $(n=489)$ or low $\operatorname{IBL}(n=1,108)$. The clinicopathological features of the patients with low and high IBL are presented in Table I. There were significant differences in the tumor site, sex, body mass index (BMI), operative approach, tumor remnant, and pathological tumor depth. Compared with the low IBL group, the high IBL group had more male patients, rectal lesions, obese cases with a BMI of $30 \mathrm{~kg} / \mathrm{m}^{2}$ or more, laparotomy cases, more residual cancer and $\mathrm{T} 4$ cases.

Regarding the short-term outcomes of patients, the operative time was $>3$ hours in $23.5 \%$ of the patients in the high IBL group and in $10.4 \%$ of the patients in the low IBL group $(p<0.001)$. Furthermore, the incidence of grade III or more postoperative complications in the group with high IBL was higher than that of the low IBL group $(78.2 \% \mathrm{vs} .30 .3 \%$, $p<0.001)$.

Evaluation of the effect of IBL on survival. Low IBL was associated with a significant survival benefit. The 5-year DFS rate was $77.8 \%$ and $63.4 \%$ for the low and high IBL groups, respectively $(p<0.001)$ (Figure 2$)$. The 5-year OS rates of the low and high IBL group was $96.7 \%$ and $93.4 \%$, respectively ( $p=0.006$ ) (Figure 3 ). Eight clinicopathological background factors were included in the multivariate analysis, which revealed that IBL was independently associated with both OS and DFS (Table II and Table III). 
Table I. Comparison of clinicopathological factors according to intraoperative blood loss (IBL) using a cut-off of $200 \mathrm{ml}$.

\begin{tabular}{|c|c|c|c|c|c|c|}
\hline \multirow[b]{2}{*}{ Factor } & & \multicolumn{4}{|c|}{ IBL, n $(\%)$} & \multirow[b]{2}{*}{$p$-Value } \\
\hline & & \multicolumn{2}{|c|}{ Low $(n=1108)$} & \multicolumn{2}{|c|}{ High $(n=489)$} & \\
\hline \multirow[t]{2}{*}{ Age } & $<75$ Years & 644 & $(58.0)$ & 299 & $(61.1)$ & 0.234 \\
\hline & $\geq 75$ Years & 467 & $(42.0)$ & 190 & $(38.9)$ & \\
\hline \multirow[t]{2}{*}{ Gender } & Male & 600 & $(54.2)$ & 314 & $(64.2)$ & $<0.001$ \\
\hline & Female & 508 & $(45.8)$ & 175 & $(35.8)$ & \\
\hline \multirow[t]{2}{*}{ Lymph node metastasis } & Absent & 584 & $(52.6)$ & 263 & $(53.9)$ & 0.637 \\
\hline & Present & 526 & $(47.4)$ & 225 & $(46.1)$ & \\
\hline \multirow[t]{2}{*}{ Site of tumor } & Colon & 771 & $(77.2)$ & 208 & $(55.5)$ & $<0.001$ \\
\hline & Rectum & 228 & $(22.8)$ & 167 & $(44.5)$ & \\
\hline \multirow[t]{2}{*}{ BMI } & $<30 \mathrm{~kg} / \mathrm{m}^{2}$ & 911 & $(98.1)$ & 413 & (94.9) & 0.001 \\
\hline & $\geq 30 \mathrm{~kg} / \mathrm{m}^{2}$ & 18 & $(1.9)$ & 22 & $(5.1)$ & \\
\hline \multirow[t]{2}{*}{ Operation approach } & Open & 710 & $(63.9)$ & 451 & $(92.2)$ & $<0.001$ \\
\hline & Lap, Rob & 401 & $(36.1)$ & 38 & $(7.8)$ & \\
\hline \multirow[t]{2}{*}{ Tumor remnant } & R0 & 1075 & $(96.8)$ & 432 & $(88.3)$ & $<0.001$ \\
\hline & $\mathrm{R} 1$ & 36 & $(3.2)$ & 57 & (11.7) & \\
\hline \multirow[t]{2}{*}{ Lymph node dissection } & D2 & 530 & $(47.7)$ & 225 & $(46.2)$ & 0.569 \\
\hline & D3 & 580 & $(52.3)$ & 262 & $(53.8)$ & \\
\hline \multirow[t]{2}{*}{ Complications (grade >III) } & Absent & 996 & $(89.6)$ & 374 & $(76.5)$ & $<0.001$ \\
\hline & Present & 115 & $(10.4)$ & 115 & $(23.5)$ & \\
\hline \multirow[t]{2}{*}{ T-Factor } & $\mathrm{T} 1-3$ & 811 & $(73.1)$ & 326 & $(66.7)$ & 0.009 \\
\hline & $\mathrm{T} 4$ & 298 & $(26.9)$ & 163 & $(33.3)$ & \\
\hline \multirow[t]{2}{*}{ Operative time } & $<3 \mathrm{~h}$ & 666 & $(61.7)$ & 132 & $(29.8)$ & $<0.001$ \\
\hline & $\geq 3 \mathrm{~h}$ & 414 & $(38.3)$ & 311 & $(70.2)$ & \\
\hline
\end{tabular}

BMI: Body mass index; Lap: laparoscopic-assisted; Rob: robotic-assisted.

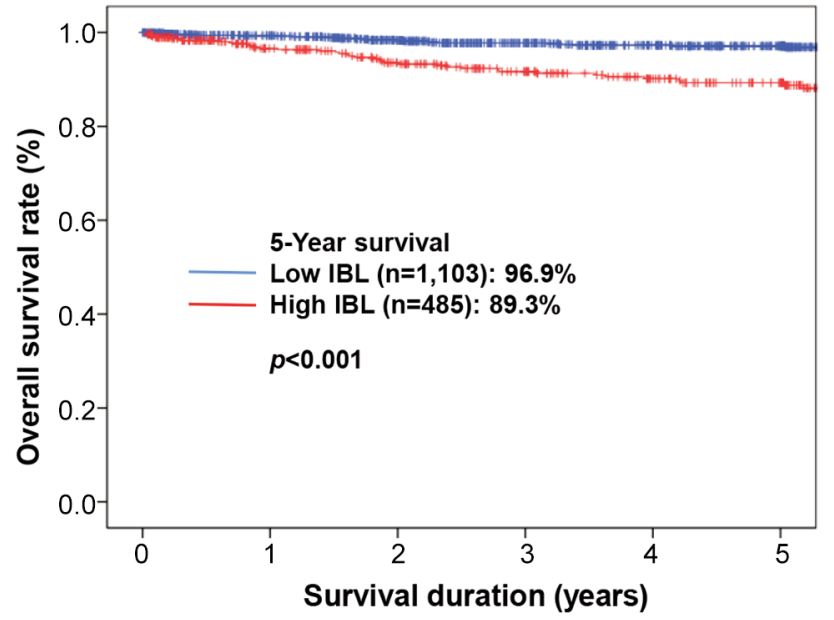

Figure 2. Recurrence-free survival rates in the groups with high $(\geq 200$ $\mathrm{ml})$ and low $(<200 \mathrm{ml})$ intraoperative blood loss $(\mathrm{IBL})$. The study population consisted of patients who underwent potentially curative surgery for stage II/III colorectal cancer.

Recurrence patterns. The sites of initial recurrence are shown in Table IV. In both groups, liver metastasis was the most frequent type of recurrence. A chi-square test revealed that the rates of lymph node recurrence and local site recurrence were significantly higher in the group with high IBL $(p<0.001)$.

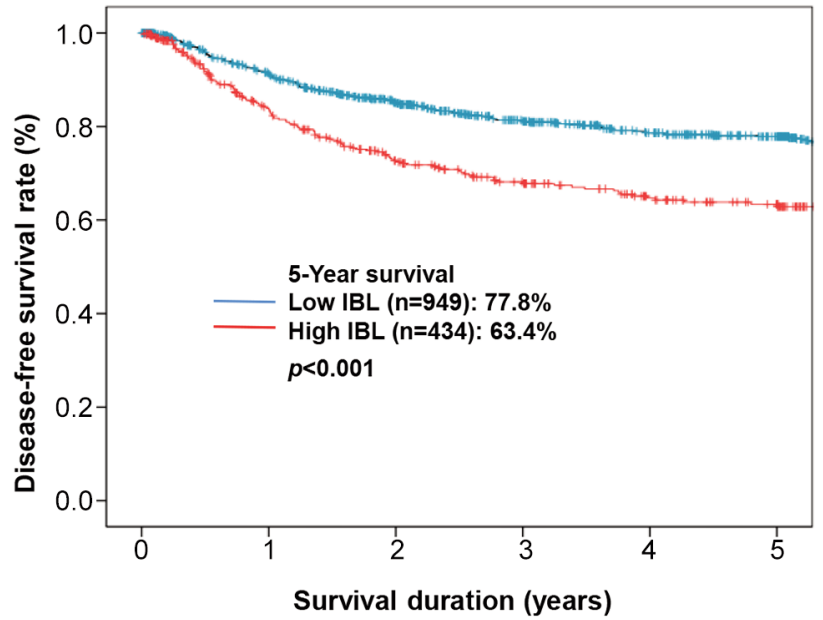

Figure 3. Overall survival rates in the high $I B L(\geq 200 \mathrm{ml})$ and low $I B L(<200 \mathrm{ml})$ groups. The study population consisted of patients who underwent potentially curative surgery for stage II/III colorectal cancer.

\section{Discussion}

In this study, which was based on a subgroup analysis of data from more than 1,500 cases, we showed that IBL $\geq 200$ $\mathrm{ml}$ was an independent risk factor for poor OS and DFS, as 
Table II. Univariate and multivariate Cox proportional hazards analysis of clinicopathological factors for disease-free survival of patients after colorectal cancer surgery.

\begin{tabular}{|c|c|c|c|c|c|c|c|}
\hline \multirow[b]{2}{*}{ Factor } & \multirow[b]{2}{*}{ Subgroup } & \multicolumn{3}{|c|}{ Univariate analysis } & \multicolumn{3}{|c|}{ Multivariate analysis } \\
\hline & & OR & $95 \% \mathrm{CI}$ & $p$-Value & OR & $95 \% \mathrm{CI}$ & $p$-Value \\
\hline \multirow[t]{2}{*}{ Age } & $<75$ Years & 1.000 & & & 1.000 & & \\
\hline & $\geq 75$ Years & 0.999 & $0.797-1.253$ & 0.994 & 1.079 & $0.855-1.362$ & 0.520 \\
\hline \multirow[t]{2}{*}{ Gender } & Male & 1.000 & & & 1.000 & & \\
\hline & Female & 0.802 & $0.641-1.002$ & 0.052 & 0.827 & $0.658-1.039$ & 0.103 \\
\hline \multirow[t]{2}{*}{ Lymph node metastasis } & Absent & 1.000 & & & 1.000 & & \\
\hline & Present & 2.526 & $2.001-3.189$ & $<0.001$ & 2.378 & $1.870-3.023$ & $<0.001$ \\
\hline \multirow[t]{2}{*}{ T-Factor } & $\mathrm{T} 1-3$ & 1.000 & & & 1.000 & & \\
\hline & $\mathrm{T} 4$ & 2.614 & $2.102-3.250$ & $<0.001$ & 2.108 & $1.671-2.660$ & $<0.001$ \\
\hline \multirow[t]{2}{*}{ Tumor remnant } & R0 & 1.000 & & & 1.000 & & \\
\hline & $\mathrm{R} 1$ & 2.370 & $1.676-3.351$ & $<0.001$ & 1.243 & $0.863-1.792$ & 0.243 \\
\hline \multirow[t]{2}{*}{ Operative approach } & Open & 1.000 & & & 1.000 & & \\
\hline & Lap, Rob & 0.744 & $0.562-0.986$ & 0.040 & 0.929 & $0.673-1.282$ & 0.652 \\
\hline \multirow[t]{2}{*}{ Lymph node dissection } & $\mathrm{D} 2$ & 1.000 & & & 1.000 & & \\
\hline & D3 & 0.955 & $0.766-1.190$ & 0.679 & 0.939 & $0.743-1.188$ & 0.602 \\
\hline \multirow{2}{*}{ IBL } & $<200 \mathrm{ml}$ & 1.000 & & & 1.000 & & \\
\hline & $\geq 200 \mathrm{ml}$ & 1.803 & $1.442-2.255$ & $<0.001$ & 1.713 & $1.348-2.178$ & $<0.001$ \\
\hline
\end{tabular}

IBL: Intraoperative blood loss; Lap: laparoscopic-assisted; Rob: robotic-assisted.

Table III. Univariate and multivariate Cox proportional hazards analysis of clinicopathological factors for overall survival of patients after colorectal cancer surgery.

\begin{tabular}{|c|c|c|c|c|c|c|c|}
\hline \multirow[b]{2}{*}{ Factor } & \multirow[b]{2}{*}{ Subgroup } & \multicolumn{3}{|c|}{ Univariate analysis } & \multicolumn{3}{|c|}{ Multivariate analysis } \\
\hline & & OR & $95 \%$ CI & $p$-Value & OR & $95 \%$ CI & $p$-Value \\
\hline \multirow[t]{2}{*}{ Age } & $<75$ Years & 1.000 & & & 1.000 & & \\
\hline & $\geq 75$ Years & 1.814 & $1.163-2.827$ & 0.009 & 2.334 & $1.454-3.746$ & $<0.001$ \\
\hline \multirow[t]{2}{*}{ Gender } & Male & 1.000 & & & 1.000 & & \\
\hline & Female & 0.636 & $0.400-1.012$ & 0.056 & 0.755 & $0.468-1.218$ & 0.250 \\
\hline \multirow[t]{2}{*}{ Lymph node metastasis } & Absent & 1.000 & & & 1.000 & & \\
\hline & Present & 2.120 & $1.339-3.358$ & 0.001 & 1.869 & $1.163-3.004$ & 0.010 \\
\hline \multirow[t]{2}{*}{ T-Factor } & $\mathrm{T} 1-3$ & 1.000 & & & 1.000 & & \\
\hline & $\mathrm{T} 4$ & 2.547 & $1.640-3.954$ & $<0.001$ & 1.739 & $1.080-2.799$ & 0.023 \\
\hline \multirow[t]{2}{*}{ Tumor remnant } & R0 & 1.000 & & & 1.000 & & \\
\hline & $\mathrm{R} 1$ & 4.206 & $2.448-7.226$ & $<0.001$ & 2.533 & $1.407-4.561$ & 0.002 \\
\hline \multirow[t]{2}{*}{ Operative approach } & Open & 1.000 & & & 1.000 & & \\
\hline & Lap, Rob & 0.680 & $0.374-1.237$ & 0.206 & 0.629 & $0.308-1.285$ & 0.204 \\
\hline \multirow[t]{2}{*}{ Lymph node dissection } & D2 & 1.000 & & & 1.000 & & \\
\hline & D3 & 2.814 & $1.722-4.599$ & $<0.001$ & 2.894 & $1.739-4.816$ & $<0.001$ \\
\hline \multirow[t]{2}{*}{ IBL } & $<200 \mathrm{ml}$ & 1.000 & & & 1.000 & & \\
\hline & $\geq 200 \mathrm{ml}$ & 3.403 & $2.154-5.376$ & $<0.001$ & 2.730 & $1.647-4.524$ & $<0.001$ \\
\hline
\end{tabular}

IBL: Intraoperative blood loss; Lap: laparoscopic-assisted; Rob: robotic-assisted.

well as postoperative morbidity, in patients with stage II/III CRC who underwent radical surgery. The results support the hypothesis that IBL affects the long-term survival of patients with CRC.

In this study, there were significant differences in the distribution of tumor site, sex, body mass index, operative approach, tumor remnant and pathological depth. The fact that male patients bled more was likely due to the fact that men have a narrower pelvis, which makes surgery more difficult. In the TNM classification, the T-stage may have influenced the amount of bleeding because surgery for advanced $\mathrm{T}$-stage cancer is likely to require more extensive 
Table IV. Comparison of patterns of recurrence between groups with high and low intraoperative blood loss (IBL) during colorectal cancer surgery.

\begin{tabular}{lrccr}
\hline & & \multicolumn{2}{c}{ IBL, n (\%) } & \\
\cline { 3 - 4 } Factor & All cases & Low (n=88) & High (n=34) & $p$-Value \\
\hline $\begin{array}{l}\text { Site of recurrence } \\
\quad \text { Lymph node }\end{array}$ & 53 & $25(2.3)$ & $28(5.7)$ & $<0.001$ \\
$\quad$ Local & 70 & $29(2.6)$ & $41(8.4)$ & $<0.001$ \\
$\begin{array}{l}\text { Distant site } \\
\quad \text { Lung }\end{array}$ & 74 & $50(4.5)$ & $24(4.6)$ & 0.721 \\
$\quad$ Liver & 128 & $81(7.3)$ & $47(9.6)$ & 0.115 \\
$\quad$ Bone & 21 & $9(0.8)$ & $12(2.5)$ & 0.008 \\
$\begin{array}{l}\text { Disseminated } \\
\quad \text { Yes }\end{array}$ & 54 & $33(3.0)$ & $21(4.3)$ & 0.117 \\
\hline
\end{tabular}

dissection. The volume of IBL for patients with CRC and preexisting anemia are the most important factors in decisions relating to blood transfusion. Blood transfusion has been demonstrated to increase the risk for complications (13), mainly infectious complications, as well as the risk for recurrence (14). It remains unclear why IBL is associated with morbidity and low survival. It has been reported, based on animal experiments, that the activity or cytotoxicity of natural killer cells was depressed after blood loss, and that the degree of reduction was correlated with the amount of blood loss $(15,16)$. IBL has been reported to be associated with the prognosis of several types of digestive carcinoma. In hepatocellular carcinoma, Katz et al. reported increased IBL during hepatic resection to be an independent prognostic factor for tumor recurrence and death (10). In pancreatic cancer, Tamagawa et al. showed that IBL $\geq 1,000 \mathrm{ml}$ was an independent risk factor for poor OS and DFS, as well as postoperative morbidity, in patients with stage II/III pancreatic cancer who underwent radical surgery (17). Nagai et al. also reported that IBL was a prognostic determinant of survival after surgery for pancreatic cancer and that operative blood loss can be used to stratify the risk of pancreatic cancer mortality (7). In gastric cancer, Liang et al. reported that IBL is an independent prognostic factor for gastric cancer after curative resection (8). Reducing IBL can improve the longterm outcomes of patients after curative gastrectomy for gastric cancer. Ito et al. also reported that IBL adversely influenced the long-term outcomes of patients with stage II/III gastric cancer (9). On the other hand, it was also reported that the minimization of IBL was very important but not an independent prognostic factor for patients with cancer $(18,19)$. There have been very few articles about the association between IBL and the long-term outcomes of CRC. Mörner et al. reported that the degree of blood loss during colon cancer surgery is a factor that influences long-term survival (20) and Okumura et al. reported that a high volume of IBL significantly affects postoperative morbidity, OS, and recurrence in elderly patients with CRC (21). Regarding the site of recurrence in our study, the rates of lymph node recurrence and local site recurrence were significantly higher in the group with high IBL. This suggests that local resection and lymph node dissection for advanced cancer are inadequate for patients with high intraoperative bleeding.

The present study was associated with some limitations. Firstly, this was a retrospective study of a single study group; thus, the findings need to be confirmed in another large-scale prospective validation study. Secondly, there was no uniform threshold for IBL. Therefore, different statistical methods may obtain different values. The distribution of blood loss was divided into two groups using an optimal cut-off point (200 ml) for classification based on the ROC curve analysis. Previous reports discussing the relationship between longterm prognosis and bleeding volume in patients during surgery for CRC reported using cut-off values of 200-800 ml $(20-22)$. Thirdly, the performance of different postoperative therapies might have had a confounding effect.

In conclusion, the long-term outcomes, such as OS and DFS, of patients with stage II/III CRC who underwent curative resection significantly differed according to the amount of IBL. The results of this study suggest that the reduction of IBL has the potential to improve the prognosis of patients with stage II/III CRC.

\section{Conflicts of Interest}

The Authors declare no conflicts of interest in association with the present study.

\section{Authors' Contributions}

All Authors contributed to the study conception and design. Data collection was performed by all Authors. The statistical analysis was performed by Toru Aoyama. The first draft of the article was written by Hiroshi Tamagawa, and all Authors commented on previous versions of the article. All Authors read and approved the final article.

\section{Acknowledgements}

This work was supported, in part, by the following nongovernmental organizations: Yokohama Surgical Research Group, Association of Healthcare Corporations, Yoshiki Dermatology Clinic Ginza, and Social Health Corporation Foundation Pond Friends Association (Fukuoka Wajiro Hospital).

\section{References}

1 Bray F, Ferlay J, Soerjomataram I, Siegel RL, Torre LA and Jemal A: Global cancer statistics 2018: GLOBOCAN estimates of incidence and mortality worldwide for 36 cancers in 185 countries. CA Cancer J Clin 68(6): 394-424, 2018. PMID: 30207593. DOI: $10.3322 /$ caac.21492 
2 O'Connell JB, Maggard MA and Ko CY: Colon cancer survival rates with the new American Joint Committee on Cancer sixth edition staging. J Natl Cancer Inst 96(19): 1420-1425, 2004. PMID: 15467030. DOI: 10.1093/jnci/djh275

3 Kim MB, Hong TS and Wo JY: Treatment of stage II-III rectal cancer patients. Curr Oncol Rep 16(1): 362, 2014. PMID: 24323626. DOI: 10.1007/s11912-013-0362-0

4 Oki E, Ando K, Kasagi Y, Zaitsu Y, Sugiyama M, Nakashima Y, Sonoda H, Ohgaki K, Saeki H and Maehara Y: Recent advances in multidisciplinary approach for rectal cancer. Int J Clin Oncol 20(4): 641-649, 2015. PMID: 26100273. DOI: 10.1007/s10147015-0858-8

5 Burrows L and Tartter P: Effect of blood transfusions on colonic malignancy recurrent rate. Lancet 2(8299): 662, 1982. PMID: 6125797. DOI: 10.1016/s0140-6736(82)92764-7

6 Kanda M, Kobayashi D, Tanaka C, Iwata N, Yamada S, Fujii T, Nakayama G, Sugimoto H, Koike M, Nomoto S, Murotani K, Fujiwara $\mathrm{M}$ and Kodera $\mathrm{Y}$ : Adverse prognostic impact of perioperative allogeneic transfusion on patients with stage II/III gastric cancer. Gastric Cancer 19(1): 255-263, 2016. PMID: 25563579. DOI: 10.1007/s10120-014-0456-x

7 Nagai S, Fujii T, Kodera Y, Kanda M, Sahin TT, Kanzaki A, Yamada S, Sugimoto H, Nomoto S, Takeda S, Morita S and Nakao A: Impact of operative blood loss on survival in invasive ductal adenocarcinoma of the pancreas. Pancreas 40(1): 3-9, 2011. PMID: 20881897. DOI: 10.1097/MPA.0b013e3181f7147a

8 Liang YX, Guo HH, Deng JY, Wang BG, Ding XW, Wang XN, Zhang $\mathrm{L}$ and Liang $\mathrm{H}$ : Impact of intraoperative blood loss on survival after curative resection for gastric cancer. World $\mathrm{J}$ Gastroenterol 19(33): 5542-5550, 2013. PMID: 24023499. DOI: 10.3748/wjg.v19.i33.5542

9 Ito $\mathrm{Y}$, Kanda M, Ito S, Mochizuki Y, Teramoto H, Ishigure K, Murai $\mathrm{T}$, Asada $\mathrm{T}$, Ishiyama A, Matsushita $\mathrm{H}$, Tanaka $\mathrm{C}$, Kobayashi D, Fujiwara M, Murotani K and Kodera Y: Intraoperative blood loss is associated with shortened postoperative survival of patients with stage II/III gastric cancer: analysis of a multi-institutional dataset. World J Surg 43(3): 870877, 2019. PMID: 30377722. DOI: 10.1007/s00268-018-4834-0

10 Katz SC, Shia J, Liau KH, Gonen M, Ruo L, Jarnagin WR, Fong Y, D'Angelica MI, Blumgart LH and Dematteo RP: Operative blood loss independently predicts recurrence and survival after resection of hepatocellular carcinoma. Ann Surg 249(4): 617-623, 2009. PMID: 19300227. DOI: 10.1097/SLA.0b013e31819ed22f

11 Chen JS, Huang JQ, Chen XL, Zhan GF and Feng JT: Risk factors associated with intraoperative major blood loss during resection of hepatocellular carcinoma. Hepatogastroenterology 62(140): 790-793, 2015. PMID: 26902002.

12 Clavien PA, Barkun J, de Oliveira ML, Vauthey JN, Dindo D, Schulick RD, de Santibañes E, Pekolj J, Slankamenac K, Bassi C, Graf R, Vonlanthen R, Padbury R, Cameron JL and Makuuchi M: The Clavien-Dindo classification of surgical complications: five-year experience. Ann Surg 250(2): 187-196, 2009. PMID: 19638912. DOI: 10.1097/SLA.0b013e3181b13ca2
13 Jagoditsch M, Pozgainer P, Klingler A and Tschmelitsch J: Impact of blood transfusions on recurrence and survival after rectal cancer surgery. Dis Colon Rectum 49(8): 1116-1130, 2006. PMID: 16779711. DOI: 10.1007/s10350-006-0573-7

14 Amato A and Pescatori M: Perioperative blood transfusions for the recurrence of colorectal cancer. Cochrane Database Syst Rev (1): CD005033, 2006. PMID: 16437512. DOI: 10.1002/ 14651858.CD005033.pub2

15 Angele MK and Faist E: Clinical review: immunodepression in the surgical patient and increased susceptibility to infection. Crit Care 6(4): 298-305, 2002. PMID: 12225603. DOI: 10.1186/ cc1514

16 Hoynck van Papendrecht MA, Busch OR, Jeekel J and Marquet RL: The influence of blood loss on tumour growth: effect and mechanism in an experimental model. Neth J Surg 43(4): 85-88, 1991. PMID: 1944994.

17 Tamagawa H, Aoyama T, Yamamoto N, Kamiya M, Murakawa M, Atsumi Y, Numata M, Kazama K, Hara K, Yukawa N, Rino $\mathrm{Y}$, Masuda $\mathrm{M}$ and Morinaga S: the impact of intraoperative blood loss on the survival of patients with stage II/III pancreatic cancer. In Vivo 34(3): 1469-1474, 2020. PMID: 32354948. DOI: 10.21873/invivo.11931

18 Arima K, Hashimoto D, Okabe H, Inoue R, Kaida T, Higashi T, Taki K, Nitta H, Hayashi H, Chikamoto A, Beppu T and Baba $\mathrm{H}$ : Intraoperative blood loss is not a predictor of prognosis for pancreatic cancer. Surg Today 46(7): 792-797, 2016. PMID: 26302976. DOI: $10.1007 / \mathrm{s} 00595-015-1238-8$

19 Zhao B, Huang X, Lu H, Zhang J, Luo R, Xu H and Huang B: Intraoperative blood loss does not independently affect the survival outcome of gastric cancer patients who underwent curative resection. Clin Transl Oncol 21(9): 1197-1206, 2019. PMID: 30689183. DOI: 10.1007/s12094-019-02046-6

20 Mörner ME, Gunnarsson U, Jestin P and Svanfeldt M: The importance of blood loss during colon cancer surgery for longterm survival: an epidemiological study based on a population based register. Ann Surg 255(6): 1126-1128, 2012. PMID: 22498893. DOI: $10.1097 /$ SLA.0b013e3182512df0

21 Okamura R, Hida K, Hasegawa S, Sakai Y, Hamada M, Yasui M, Hinoi T, Watanabe M and Japan Society of Laparoscopic Colorectal Surgery: Impact of intraoperative blood loss on morbidity and survival after radical surgery for colorectal cancer patients aged 80 years or older. Int J Colorectal Dis 31(2): 327334, 2016. PMID: 26412248. DOI: 10.1007/s00384-015-2405-5

22 Egenvall M, Mörner M, Påhlman L and Gunnarsson U: Degree of blood loss during surgery for rectal cancer: a populationbased epidemiologic study of surgical complications and survival. Colorectal Dis 16(9): 696-702, 2014. PMID: 24720780. DOI: $10.1111 /$ codi.12630

Received July 27, 2021

Revised September 17, 2021

Accepted September 21, 2021 